\title{
A case of asynchronous bilateral cancer of the oral commissure
}

\author{
Imaizumi $T^{1}$, Ooishi $M^{1}$, Irie $H^{1}$, Inoue $T^{2}$, Narisawa $Y^{2}$ and Yamaguchi $Y^{3}$ \\ ${ }^{1}$ Department of Radiology, Saga University, Japan \\ ${ }^{2}$ Department of Dermatology, Saga University, Japan \\ ${ }^{3}$ Department of Oral Surgery, Saga University, Japan
}

\begin{abstract}
Cancer of the oral commissure is a rare form of lip cancer. We treated a 72-year-old female patient who underwent radiotherapy for lip cancer of the oral commissure and developed cancer of the opposite oral commissure six years later. The patient noticed a swelling in the right oral commissure that was diagnosed by biopsy as squamous cell carcinoma. Intra-arterial chemotherapy and concomitant radiotherapy (66 Gy) were performed. After this treatment, complete remission (CR) of the local lesion was achieved. Six years post-treatment, a nodular lesion appeared in the opposite oral commissure that was also diagnosed by biopsy as squamous cell carcinoma. There was no continuity with the previously treated area, and double carcinoma was diagnosed. Because the affected area had received approximately 30 Gy of irradiation during the previous treatment, $60 \mathrm{~Gy}$ of radiotherapy was administered by the hyperfractionation method to reduce late side effects.
\end{abstract}

\section{Introduction}

In Western nations, lip cancer accounts for $15 \%-30 \%$ of all oral cancers; however, lip cancer is far less common in Japan, accounting for only $0.9 \%-3.6 \%$ of oral cancers (references ) [1-3]. Lip cancer usually occurs in the lower lip, and is rarely seen in the oral commissure [35]. Histologically, most cases are squamous cell carcinoma [6]. To our knowledge, only one case of bilateral squamous cell carcinoma of the oral commissure has previously been reported [7].

Here, we report a case of asynchronous bilateral lip cancer of the oral commissure in an elderly female patient who underwent radiotherapy.

\section{Case Report}

The patient was a 72-year-old woman who noticed repeated laceration of the right oral commissure 11 years before presentation. A nodule that had gradually increased in size had become apparent three years before presentation. On initial presentation, an elevated lesion 2 $\mathrm{cm}$ in size that extended from the right oral commissure to the buccal mucosa was noted (Figure 1). The lesion was diagnosed by biopsy as squamous cell carcinoma, and was assessed as cT1N0M0 without lymph node metastasis or distant metastasis. Arterial injection and concomitant radiotherapy ( $66 \mathrm{~Gy}$ ) of the area were performed. A total of $66 \mathrm{~Gy}$ of radiation was delivered by $4 \mathrm{MV}$ X-ray in 33 fractions of 2 Gy (Figure 2). A spacer was used to prevent tongue exposure. A total of four doses of CDDP at $100 \mathrm{mg} / \mathrm{m}^{2}$ wass administered as intra-arterial chemotherapy.. After completion of this treatment, complete remission (CR) of the local lesion was achieved (Figure 3). In the first year after treatment, a whitish lesion appeared with its center in the opposite (left) oral commissure. The lesion was positive for Candida and was treated as candidiasis and monitored. In the sixth year after treatment, a white nodule with leukoplastic lesions in the surrounding buccal and labial mucosa appeared in the left oral commissure (Figure 4). The lesion in the oral commissure was diagnosed by biopsy as squamous cell carcinoma, and the surrounding leukoplastic lesions as carcinoma in situ in site. Because there was no obvious recurrence in the right oral commissure and no continuity with the later lesion, it was considered to represent double cancer. During the previous treatment, the affected right area had received approximately $30 \mathrm{~Gy}$ of irradiation; therefore, radiotherapy was administered by the hyperfractionation method to reduce late side effects. A total of $60 \mathrm{~Gy}$ of radiation was delivered by 4 MV X-ray in 50 fractions of $1.2 \mathrm{~Gy}$ (2 fractions per day). The treatment was completed without the occurrence of any particular serious acutephase side effects. The status immediately after treatment was CR.

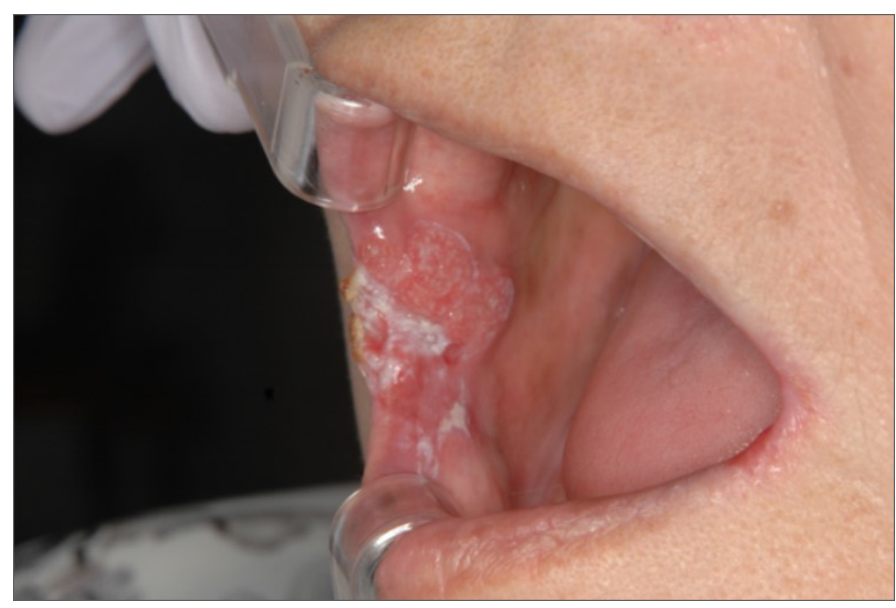

Figure 1. Before the initial treatment. A swelling extending from the right oral commissure to the buccal mucosa was diagnosed as squamous cell carcinoma.

${ }^{*}$ Correspondence to: Takeshi Imaizumi, Department of Radiology, Saga University, 5-1-1 Nabeshima, Saga 849-8501, Japan, Tel: +81-952-34-2309; Fax: +81-952-34-2016; E-mail: imaizumt@cc.saga-u.ac.jp

Key words: oral cancer, radiotherapy, double cancer

Received: May 20, 2018; Accepted: May 28, 2018; Published: May 31, 2018 


\section{Discussion}

Alcohol and smoking are among the risk factors for lip cancer (reference) [8,9], but this patient neither drank nor had ever smoked. Exposure to sunlight is another risk factor (reference) $[8,10]$ but there was nothing in the personal or occupational history of our patient suggesting that such exposure might have been a particular risk. Laceration and infection of the oral commissure had occurred some years before, and long-term external irritation may have contributed to the development of cancer.

It is unclear why carcinoma developed in the oral commissures on both sides; however, during radiotherapy for the first cancer, the opposite oral commissure was exposed to radiation, which may have influenced the development of the later lesion. There have been numerous reports of radiation-induced cancers; for example, Amemiya et al. calculated that the incidence of radiation-induced cancer after

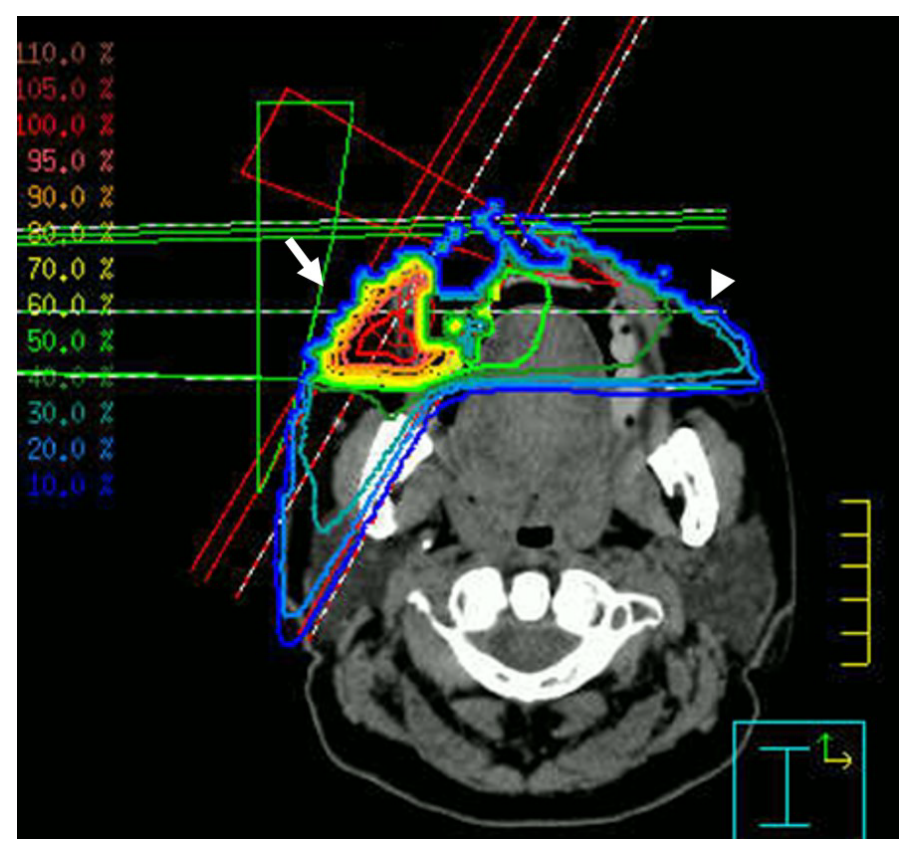

Figure 2. Radiotherapy was used to treat the cancer of the right oral commissure (arrow). The left oral commissure received approximately $30 \mathrm{~Gy}$ of radiation exposure (arrowhead).

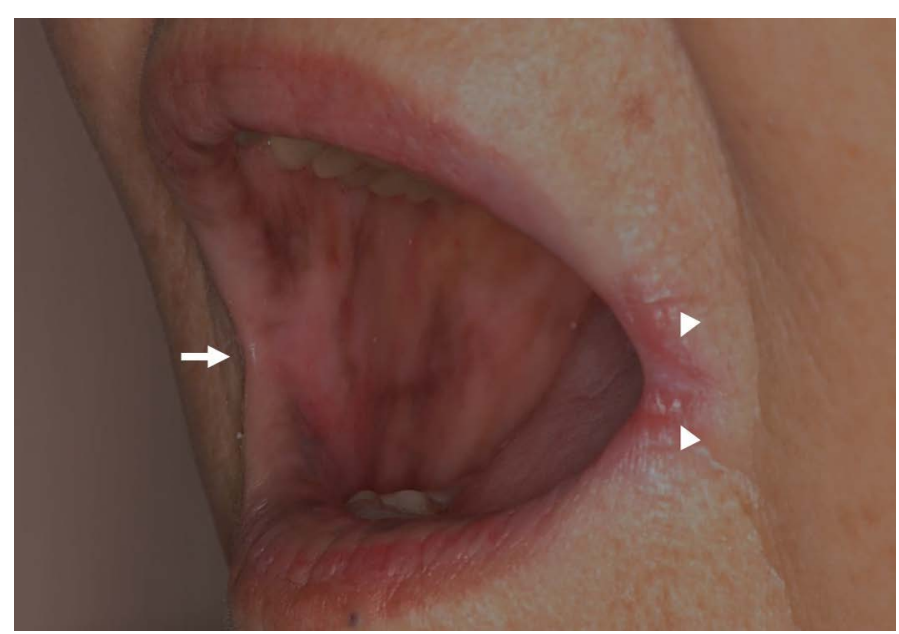

Figure 3. Four years after the initial treatment. No obvious recurrence in the right oral commissure is visible (arrow). There was a whitish lesion in the left oral commissure, which was diagnosed as candidiasis (arrowhead).

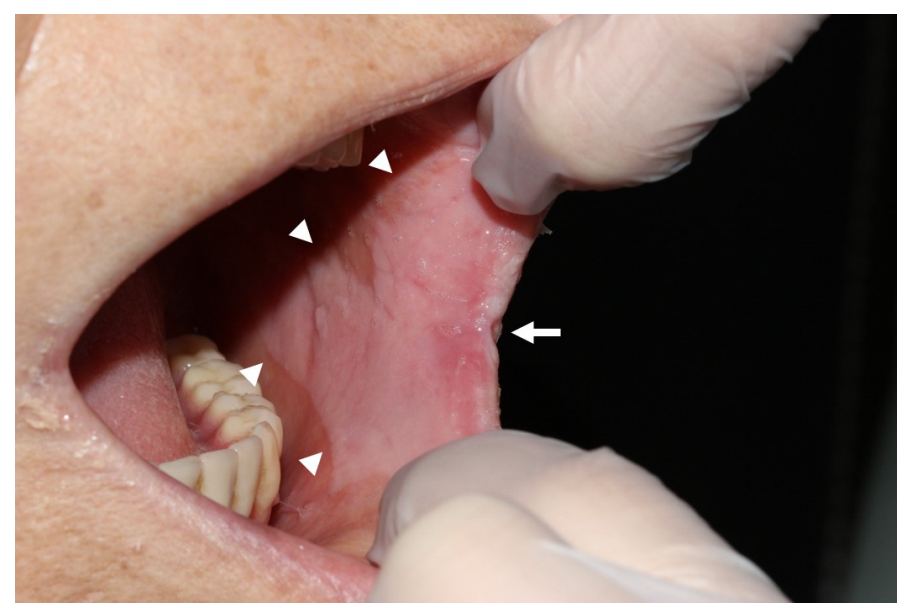

Figure 4. Six years after the initial treatment. Squamous cell carcinoma was present in the left oral commissure (arrow). A leukoplastic lesion in the surrounding mucosa was diagnosed by biopsy as carcinoma in situ (arrowhead).

radiotherapy for head and neck cancer is $1.6 \%$ after 10 years [11]. Rennie et al. also reported a case of fibrosarcoma of the lip that occurred approximately 50 years after radiotherapy for squamous cell carcinoma of the lip [12]. In general, radiation-induced solid cancers take many years to develop (reference) $[11,13]$. Such cancers are usually defined as a different histological type from the original cancer [14] (reference); however, this was not the case in our patient. This case is difficult to explain exclusively in terms of radiation-induced cancer, and the later lesion may have developed as the result of a combination of various factors.

Cancer of the lip may be treated with surgery, radiotherapy, or a combination of both [15]. In $90 \%$ of the cases, lip cancers are discovered at an early stage (reference) [15]. The outcomes of surgery and radiotherapy are almost equivalent for early-stage carcinoma. The five-year recurrence-free survival rate for $\mathrm{T} 1$ and $\mathrm{T} 2$ cancer of the lip after radiotherapy is $90 \%$ (reference) [16]. In our patient, the lesion was $\mathrm{T} 1$; therefore, the standard therapy would have been radiotherapy alone. However, intra-arterial chemotherapy was also used to improve local control. Wu et al. reported that $62 \% \mathrm{CR}$ was achieved by treating T3-4 cancer of the oral commissure with combined intra-arterial chemotherapy and radiotherapy [17].

The later lesion had received approximately 30 Gy of radiation exposure during the previous radiotherapy (Figure 2). If the same dose as used in the initial treatment had been administered by normal fractionation during the treatment of the second cancer, the total dose would have exceeded the tolerance dose for the skin and other tissues, entailing a high risk of serious late side effects. To reduce the risk of late side effects, the method of treatment was adapted by using hyperfractionation $[18,19]$.

Oral cancer has a high incidence of double cancer, and several cases of double cancer occurring in the same oral cavity have been reported [7]. However, reported cases of squamous cell carcinoma developing in the oral commissures on both sides are rare; therefore, we did not envision that cancer would develop in the opposite oral commissure. The prognosis for cancer of the lip is comparatively good, and it may be necessary to focus radiation more closely on the lesion itself by using multi-beam irradiation or brachytherapy when treating such cancers [20]. Such an adjustment would minimize the radiation exposure of normal tissue as far as possible and reduce the probability of double cancer developing in adjacent areas. 


\section{Conclusion}

We treated a patient who underwent radiotherapy for lip cancer of the oral commissure and developed cancer of the opposite oral commissure. In light of the potential development of double cancer in adjacent areas, it may be necessary to focus radiation more closely on the lesion itself during the initial treatment to limit the radiation exposure of normal tissue.

\section{References}

1. Hoffman HT, Karnell LH, Funk GF, Robinson RA, Menck HR (1998) The National Cancer Data Base report on cancer of the head and neck. Arch Otolaryngol Head Neck Surg 124: 951-962. [Crossref]

2. Canto MT, Devesa SS (2002) Oral cavity and pharynx cancer incidence rates in the United States, 1975-1998. Oral Oncol 38: 610-617. [Crossref]

3. Yamashita T, Omura K, Okumura K, Yanai C (1999) Clinical Study on 16 Lip Squamous Cell Carcinomas. J Jpn Stomatol Soc 48: 344-347.

4. Han AY, Kuan EC, Mallen-St Clair J, Alonso JE, Arshi A, et al. (2016) Epidemiology of Squamous Cell Carcinoma of the Lip in the United States: A Population-Based Cohort Analysis. JAMA Otolaryngol Head Neck Surg 142: 1216-1223. [Crossref]

5. Baker SR, Krause CJ (1980) Carcinoma of the lip. Laryngoscope 90: 19-27. [Crossref]

6. Muir C, Weiland L (1995) Upper aerodigestive tract cancers. Cancer 75: 147-153. [Crossref]

7. Oota S, Yoshimura R, Miura M, Shibuya H (2001) Japanese J Clinical Radiol 46: 318-321.

8. Tseng HW, Liou HH, Tsai KW, Ger LP, Shiue YL (2017) Clinicopathological study of lip cancer: a retrospective hospital-based study in Taiwan. APMIS 125: 1007-1016. [Crossref]

9. Najim M, Cross S, Gebski V, Palme CE, Morgan GJ, et al. (2013) Early-stage squamous cell carcinoma of the lip: the Australian experience and the benefits of radiotherapy in improving outcome in high-risk patients after resection. Head Neck 35: 1426-1430. [Crossref]
10. Tamura A, Ohnishi K, Ishikawa O, Miyachi Y (1997) Flow cytometric DNA content analysis of ultraviolet light-induced squamous cell carcinomas: a comparative study of squamous cell carcinomas of the lip and those arising from other sites of sun-damaged skin. Acta Derm Venereol 77: 425-427. [Crossref]

11. Amemiya K, Shibuya H, Yoshimura R, Okada N (2005) The risk of radiation-induced cancer in patients with squamous cell carcinoma of the head and neck and its results of treatment. Br J Radiol 78: 1028-1033. [Crossref]

12. Rennie JS, McLay A, Tanner NS (1983) Post-irradiation sarcoma of the lower lip. $J$ Laryngol Otol 97: 871-875. [Crossref]

13. Uchida M (1984) [A study of the incidental rate of the radiation-induced cancer in the head and neck region]. Gan No Rinsho 30: 1553-1560. [Crossref]

14. Sakai K, Kitamura T, Hinata H, Yamashita H (1986) Second cancers following radiotherapy for malignant tumors. Nihon Igaku Hoshasen Gakkai Zasshi 46: 811-818. [Crossref]

15. Unsal AA, Unsal AB, Henn TE, Baredes S, Eloy JA (2018) Cutaneous squamous cell carcinoma of the lip: A population-based analysis. Laryngoscope 128: 84-90. [Crossref]

16. Thanh Pham T, Cross S, Gebski V, Veness MJ (2015) Squamous cell carcinoma of the lip in Australian patients: definitive radiotherapy is an efficacious option to surgery in select patients. Dermatol Surg 41: 219-225. [Crossref]

17. Wu CF, Chang KP, Huang CJ, Chen CM, Chen CY, et al. (2014) Continuous intraarterial chemotherapy for downstaging locally advanced oral commissure carcinoma. Head Neck 36: 1027-1033. [Crossref]

18. Levendag PC, Meeuwis CA, Visser AG (1992) Reirradiation of recurrent head and neck cancers: external and/or interstitial radiation therapy. Radiother Oncol 23: 6-15. [Crossref]

19. Eisbruch A, Dawson L (1999) Re-irradiation of head and neck tumors. Benefits and toxicities. Hematol Oncol Clin North Am 13: 825-836. [Crossref]

20. Guinot JL, Arribas L, Vendrell JB, Santos M, Tortajada MI, et al. (2014) Prognostic factors in squamous cell lip carcinoma treated with high-dose-rate brachytherapy. Head Neck 36: 1737-1742. [Crossref]

Copyright: (C2018 Imaizumi T. This is an open-access article distributed under the terms of the Creative Commons Attribution License, which permits unrestricted use, distribution, and reproduction in any medium, provided the original author and source are credited. 